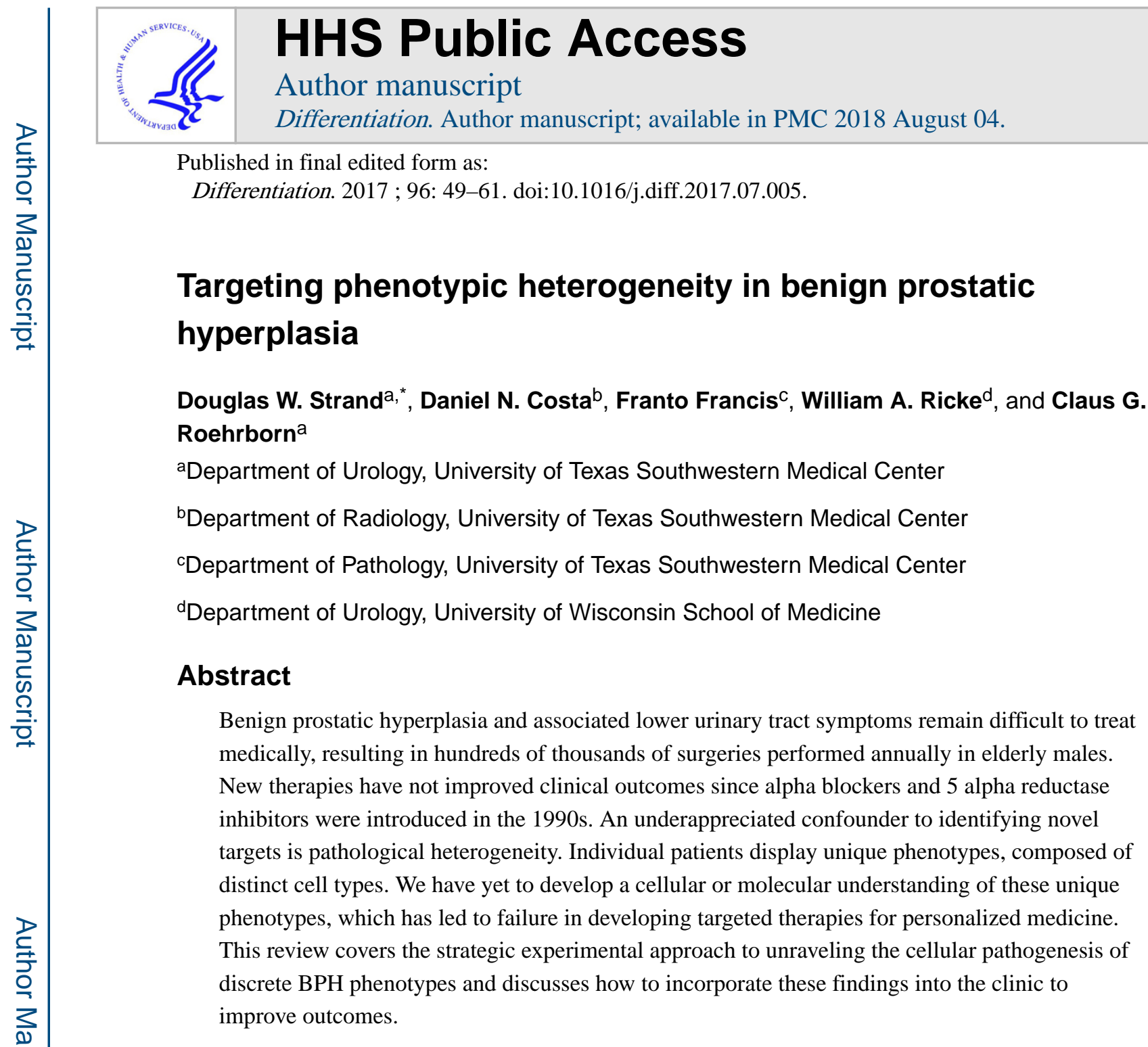

\title{
Introduction
}

Benign prostatic hyperplasia (BPH) is a slow expansion of the transition zone that results in the progressive manifestation of obstructive lower urinary tract symptoms (LUTS). The incidence rates of BPH and LUTS increase approximately $10 \%$ per decade of life starting at 40 years of age (1). Chronic progressive diseases in general are increasing along with life expectancy, where it is estimated that the number of people in the US over 80 years old will increase from 9.3 million in 2000 to 19.5 million in 2030 (2). Moreover, the number of men in the US suffering from LUTS is projected to reach 11 million by 2030 (3). The economic costs of treating LUTS is estimated at more than $\$ 4$ billion each year mainly due to increased therapeutic intervention (4). Together with an increase in comorbidities of BPH/

\footnotetext{
*Corresponding author: 5323 Harry Hines Blvd. JA5.150D, Dallas, TX 75390-9110, USA. Douglas.Strand@ UTSouthwestern.edu. Competing interests

The authors declare that they have no competing interests

Publisher's Disclaimer: This is a PDF file of an unedited manuscript that has been accepted for publication. As a service to our customers we are providing this early version of the manuscript. The manuscript will undergo copyediting, typesetting, and review of the resulting proof before it is published in its final citable form. Please note that during the production process errors may be discovered which could affect the content, and all legal disclaimers that apply to the journal pertain.
} 
LUTS $(5,6)$, the incidence and progression rates of BPH/LUTS as well as the economic burden will surely rise.

The non-diseased human prostate is about the size of a walnut and divided into four basic anatomical zones: transitional, central, peripheral, and anterior fibromuscular stroma (7). At approximately 40 years of age, the prostate transition zone begins to grow slowly at $1.6 \%$ per year, and this rate accelerates with age (8). The first clinic visit for a patient complaining of LUTS requires a detailed physical examination and history. LUTS can derive from dynamic dysfunction of bladder and prostate smooth muscle or from static bladder outlet obstruction due to prostatic enlargement (9). A digital rectal examination is typically the first indication of potential prostatic enlargement as a cause of obstructive LUTS. Once prostate cancer is ruled out, more estimations of LUTS severity are collected including uroflowmetry, symptom scores, and a measurement of prostate volume by ultrasound.

In the absence of tissue, blood or urinary biomarkers, clinical variables must be used as markers of BPH/LUTS severity and progression. Baseline variables such as age, prostate volume $>40 \mathrm{cc}$, high PSA levels, low peak flow rate, and high post-void residual (PVR) are good clinical predictors of acute urinary retention (AUR) and BPH-related surgery (10). Dynamic variables such as an increase in the AUA symptom score (AUASS) and PVR worsening are also good indicators of patients at risk of BPH progression (11). In early stage disease, modifiable risk factors are discussed for management of symptoms (12). However, when symptoms become moderate to severe (AUASS > 8), medical therapies are discussed.

Unfortunately, the few medical therapies approved for BPH/LUTS only mitigate the risk of symptomatic progression by 30-40\% across a large and diverse cohort (13). The two predominant therapies prescribed for LUTS are alpha adrenergic receptor blockers ( $\mathrm{a}$ blockers) and 5 alpha reductase inhibitors (5ARI). Alpha blockers are recommended as a first-line therapy for patients with moderate symptoms, PSA $\leq 1.5 \mathrm{ng} / \mathrm{mL}$, and a prostate volume $\leq 40 \mathrm{cc}$ (14). The mechanism of action of a-blockers is to reduce smooth muscle tone, which increases peak urinary flow rate. It is notable that the clinical response to $a-$ blockers is proportional to the percent of prostate tissue occupied by smooth muscle (15, 16), meaning that those patients with glandular hyperplasia are less likely to demonstrate a clinical response. Men with prostate volume $>40 \mathrm{cc}$ are most likely to show a clinical response to 5ARI treatment. This is likely due to the fact that larger prostates are more likely to take on the form of glandular hyperplasia (17-19), tissues that are rich in androgen receptors to which 5ARIs are targeted. The mechanism of action of 5ARIs is to reduce local dihydrotestosterone (DHT) levels by inhibiting the conversion of testosterone to DHT, causing apoptosis of luminal epithelia. 5ARI treatment reduces prostate volume by an average of $19 \%$ across a patient population, which slows the progression of lower urinary tract symptom worsening (20). Despite the availability and widespread use of these therapies, more than 250,000 men per year in the US undergo some form of surgical intervention for their obstructive LUTS (21).

Even though a-blockers and 5ARIs target specific cell types, the clinician is virtually blinded to the underlying tissue composition of prostatic growth when administering these medications. Making decisions on medical treatment is predominantly based on prostate 
volume. The evolution of prostate tissue composition with increasing volume was first surveyed in an autopsy series by Franks over 60 years ago (19). Since then there have been various attempts to classify the anatomical and cellular subtypes of prostatic growth $(22,23)$, but very little is understood about the underlying molecular pathways driving disparate cellular phenotypes. The 2008 NIDDK Prostate Strategic Plan identified a Research Priority Recommendation: develop research efforts for phenotype-specific therapies for LUTS, BPH, and prostatitis based on respective pathological criteria for enhancing efficacy, avoiding treatment failures, and improving cost effectiveness. The expectations of such research were intended to molecularly define specific "phenotypes" of patients and therefore provide a better definition of disease than the current use of clinical parameters such as PSA and prostate volume (24). Nearly 10 years later, we have yet to develop a deeper molecular and cellular understanding of BPH phenotypes.

The observed variation in clinical response to BPH medications suggests that we have yet to target the assortment of BPH pathogeneses. The purpose of this review is to clarify the experimental approach to solving the molecular underpinnings of morphological heterogeneity in BPH/LUTS in order to develop personalized treatments for this multifaceted disease.

\section{Clinical diagnosis and management of BPH/LUTS}

Up until the 1990s, the most common treatment for LUTS arising from BPH was surgical resection or enucleation of the prostate. Novel medical treatments have since surpassed surgical intervention. In the early 1990s the role of the adrenergic innervation of the bladder neck, prostate and prostatic capsule was elucidated. Based on the observation that there is a strong presence of alpha 1a receptors, the class of alpha adrenergic receptor blocker drugs was progressively introduced, which is now made up by five drugs in clinical use (terazosin, doxazosin, tamsulosin, alfuzosin and silodosin) (25). The alpha adrenergic receptor blockers (a-blockers) were developed to relieve dynamic bladder outlet obstruction by acting to relieve smooth muscle tone and were also shown to significantly reduce symptomatic progression (26).

Research at UT Southwestern demonstrated that the prostate expresses 5 alpha reductase, an enzyme that converts testosterone to its more potent derivative dihydrotestosterone (DHT) (27). The 5 alpha reductase inhibitor (5ARI) finasteride was developed and approved in 1993 to treat male LUTS secondary to BPH. It works to decrease static bladder outlet obstruction due to BPH by lowering intra-prostatic dihydrotestesterone (DHT) levels by nearly $97 \%$, which causes apoptosis of androgen-dependent luminal epithelium (28-30), a reduction in total prostate size by about $20-25 \%$, a reduction in serum PSA by about $50 \%$. The treatment is most effective in men with prostate volume $>40 \mathrm{cc}$, but typically takes several months for symptomatic improvement (31). Later, David Russell at UT Southwestern cloned and identified two 5 AR isoenzymes, type 1 and type 2, of which type 2 is more important in the prostate $(32,33)$, and inhibited by finasteride. There is a second commercially available 5ARI, dutasteride, which inhibits both types of the 5AR isoenzymes. It is unclear what molecular mechanisms drive resistance to 5ARI treatment with either 
drug. This may be due to the fact that some regions are responsive while other regions are resistant, even within the same patient (Figure 1).

Although a-blockers are considered a first-line therapy due to their fast-acting effects, longitudinal clinical trials such as MTOPS (13), CombAT (34), and PREDICT (35) demonstrated that combination therapy with an a-blocker and a 5ARI provided superior LUTS relief compared to monotherapy, particularly in men with a prostate volume greater than $40 \mathrm{cc}$. Moreover, a baseline prostate volume greater than $40 \mathrm{cc}$ and unresponsiveness to a-blocker treatment serve as key predictors of LUTS progression $(36,37)$.

One obvious observation from these clinical trials is the patient-specific response to treatments. No individual drug treatment mitigates the risk of symptomatic progression by more than $35-40 \%$ across a cohort; however, individual patients can display a range from very good to undetectable responses. This is likely due to the individual's specific tissue composition. While combination treatment with a-blockers and 5ARIs decreases the risk of symptomatic progression by $66 \%$, their combined use must be targeted to men with larger prostates to be clinically and economically superior to monotherapy with a-blockers (38). Nearly $5-7 \%$ of men that present with symptoms will eventually require surgery without medical therapy. Regardless of the treatment regimen, longitudinal trials suggest that, even on sustained treatment, symptoms will continue to worsen (albeit at a slower pace). It is also worth noting that nearly $20 \%$ of patients have such strong adverse effects from these therapies that medication must be discontinued (13). In fact, data suggest that most men do not stay on 5ARI therapy for longer than a year (39). While a-blocker monotherapy is certainly the fastest-acting and most inexpensive option, combination therapy with a 5ARI is the most cost-effective long-term medical treatment for those who can afford it, providing maximum symptomatic relief for moderate symptoms (40). For those with severe symptoms, TURP is still the most effective treatment in terms of cost and clinical outcome (41).

The efficacy of a-blockers is at least partially dependent on the percent of smooth muscle that composes the prostate (15). Although stromal hyperplasia is thought to dominate the initial phases of BPH (42-44), as prostate volume surpasses 50cc, most patients display an enlargement of glandular nodules that occupy a large percentage of the total prostate volume $(18,19,23)$.

More recently some patients with LUTS secondary to BPH are also being treated with anticholinergic drugs usually in combination with alpha blockers (45-47), as well as one drug in the PDE5 inhibitor class, tadalafil, which presumably is effective by smooth muscle relaxation as well through the NOS/NO pathway and the inhibition of the breakdown of cGMP by the ubiquitous phosphodiesterase type 5 in the prostate gland (48-51).

Stromal and glandular hyperplasia phenotypes are extremely diverse (52-55), which may represent distinct etiologies and cell types. Longitudinal trials for the treatment of LUTS have largely ignored the subtype of hyperplasia in assessing clinical impact, which could have a tremendous negative impact on the use of promising drugs that are discarded when they fail to meet their clinical goals across a large cohort. 
In summary, the clinical hurdles before us are to determine predictors of response to the different classes of medical therapy available and to determine the sequence of therapies in case of initial drug treatment failure. Clearly, being able to predict treatment response will facilitate satisfactory treatment outcomes, reduce the risk for treatment failure, improve patient satisfaction and enhance drug compliance, while being more cost effective than randomly choosing drugs for a given patient. Blinded to an individual patient's histological phenotype, however, we are currently resigned to treating patients based on prostate volume (or PSA level, the best biomarker of prostate size) until symptoms become so severe that surgical intervention is necessary. Rational interventional decisions based on sound scientific data are desperately needed to reduce symptomatic progression and reduce invasive procedures in this elderly population.

\section{Prostate cell biology and anatomy}

In order to begin deconstructing the phenotypic heterogeneity of BPH, a rudimentary understanding of human prostate cell biology and anatomy is needed. The presumptive prostate begins development as part of the ambisexual urogenital sinus until sexual dimorphism is achieved with the production of androgens (especially DHT) by the fetal testis (for a thorough review of prostate development, see (56)). Androgens activate the production of stromal 'andromedins' to drive the morphogenesis of solid buds composed of primitive epithelia, which are then canalized in a proximal to distal direction to form secretory glandular acini $(57,58)$. At this point, epithelia differentiate into basal and luminal phenotypes and the surrounding mesenchyme differentiates into fibroblasts and smooth muscle $(57,59)$.

The hierarchy of the prostate epithelium has been debated for some time (60-64). Adult, fully differentiated prostate glands are lined with a continuous layer of cuboidal basal epithelium and an adjacent secretory layer of tall columnar luminal epithelium. Historically, basal epithelia have been defined by expression of cytokeratins $5 / 14$ and luminal epithelia by cytokeratins 8/18 (65). A more detailed understanding of the function and identity of basal and luminal lineages in human prostate has recently emerged with deep sequencing of flow cytometry-isolated basal and luminal cell types (see Figure 2). Gene set enrichment analysis demonstrated that luminal epithelia sorted as Trop $2^{+} / \mathrm{CD} 49 \mathrm{f}^{\mathrm{lo}}$ displayed cytokeratin $8 / 18$ and androgen signaling as expected; however, basal epithelia sorted as Trop $2^{+} / \mathrm{CD} 49 \mathrm{f}^{\mathrm{hi}}$ showed not only classical markers such as cytokeratins 5/14, but also unexpected EMT and proneural signatures (66).

This cell surface marker-based hierarchical clustering of cell 'types' doesn't account for the probable presence of progenitor and intermediate sub-types within each master lineage (60). The $20 \%$ reduction in prostate volume achieved by luminal epithelial-targeted 5ARI treatment is reversible when the treatment is stopped $(67,68)$, which suggests a potential role for stem cells in BPH (69-71). The original evidence demonstrating the presence of resident stem cells in the prostate was published by John Isaacs in the 1980s. Here it was shown that after the luminal epithelium was atrophied by castration, regeneration of the prostate to its original size could be achieved by restoring androgen levels. This could be accomplished with indefinite rounds of castration/regeneration, and suggested the presence 
of an androgen-independent epithelial progenitor (72). Several groups have attempted to more precisely identify the cell type(s) responsible for this regeneration as this has important implications for the survival of castration-resistant tumor cells $(73,74)$. This has led to a contentious debate over the epithelial cell of origin in prostate cancer (75), but has also taught us important lessons that can be applied to our understanding of the potential cells of origin in glandular BPH phenotypes.

There have been some efforts to distinguish epithelial cell types using functional assays followed by transcriptomic analysis. These data distinguished prostate epithelia into stem, transit amplifying, committed basal and luminal cells based on the ability of primary epithelia to adhere to a matrix or by prospective sorting with cell surface markers (76). The transit amplifying or 'intermediate' epithelial population has been described as having markers of both basal $\left(\mathrm{CK} 5 / 14^{+}\right)$and luminal $\left(\mathrm{CK} 8 / 18^{+}\right)$lineages and is expanded in pathological conditions such as prostatitis $(77,78)$. It is not clear whether these 'intermediate' cells are an established cell 'type' or a cell that originated as a basal cell that has been induced to differentiate into a luminal cell (or vice-versa) and is therefore in an intermediate cell 'state'. In fact, lineage tracing experiments suggest that basal and luminal epithelial layers are predominantly maintained by lineage-specific progenitors in the adult $(79,80)$, though pathological conditions such as prostatitis are able to induce transition of a basal cell type to a luminal cell type (81). New techniques in single cell sequencing may help elucidate the relative diversity of cell types (or 'states') in a heterogeneous population, which uses a bioinformatics approach to designate transcriptomic differences between cells (82). This transcriptomic information is then paired with morphometric and lineage tracing data to define cell 'types' vs. cell 'states' (83).

In addition to glandular hyperplasia, increased prostate volume (and/or associated LUTS) can result from stromal hyperplasia (or a mixture of both) (9). The cellular hierarchy of the stroma is not well studied, although mesenchymal stem cells have been isolated from the prostate and show the potential for multi-lineage differentiation ex vivo (84). Recent evidence suggests the presence of at least 4 different stromal cell types in the prostate (85). The contribution of each of these indigenous cell types to stromal hyperplasia is poorly understood, as is the contribution of mesenchymal stem cells recruited from outside the prostate (86). The different types of prostatic hyperplasia (i.e. glandular, stromal, or mixed) beg the question of whether there are distinct cells of origin for discrete phenotypes. Identifying different cells of origin for glandular $v s$. stromal phenotypes could lead to their treatment as different diseases, even though both are associated with LUTS.

\section{Cells of origin for distinct BPH phenotypes}

'Lower urinary tract symptoms' is a term that was created to concentrate a breadth of etiologies into a single clinical category and as such has created the illusion of a single pathogenesis. LUTS can be secondary to benign prostatic enlargement, but also bladder and prostate cancers, urinary tract infection, overactive bladder, and neurologic pathologies (87). With all of the advances in the surgical treatment of symptomatic BPH (88), the failure to make strides in providing better medical management may be due to an inability to classify the pathophysiological diversity of the disease. 
Unlike prostate cancer, there are currently no recognized phenotypes that predict BPH severity or progression. Hence, biopsies are considered too high of a risk for benign disease. The expansion of prostate tissue occurs naturally in only a few mammals including dogs, humans and some primates (89). BPH causes LUTS predominantly in humans because of the presence of a unique prostatic capsule, which increases the obstructive force exerted at the bladder neck (9). To understand the spectrum of phenotypes represented in BPH, one needs to appreciate its normal anatomy, which is unique among mammals $(56,90)$.

The zonal anatomy of the human prostate was best described by the pathologist John McNeal throughout the 1970s and 80s $(7,23)$. The prostate is separated into glandular zones (transition, central, and peripheral) and a stromal zone (anterior fibromuscular stroma). In a typical 'healthy' male, the prostate is $25 \mathrm{cc}$ with the transition zone accounting for $~ 5 \%$ of the total volume (a little over 1 gram) (91). While each zone can expand with age, the majority of patients experience LUTS due to an expansion of the transition zone (23).

Despite their limitations in describing the type of benign growth, prostate volume and surrogate serum PSA levels are still the best predictors of symptomatic progression $(92,93)$. In practical terms, this means that patients with a smaller prostate volume are more likely to respond to current medical treatments, and this makes understanding and treating the diverse causes of prostatic enlargement a foremost clinical goal (93). Two potential areas of research were identified in the NIDDK Prostate Strategic Plan as having tremendous potential for improving patient care: 1) identification of biomarkers that improve the diagnosis, categorization, and prognosis of $\mathrm{BPH}$, and 2) development of disease-relevant pathways for the application of targeted therapies (24). Urinary biomarkers of LUTS are now beginning to be validated $(94,95)$, but we have yet to develop actionable molecular pathways of BPH progression. To do so, we first need to appreciate the morphological variety of prostatic growth.

The evolution of prostate tissue composition with increasing size was first recognized by Franks over 60 years ago (19). Early quantitative morphometric studies of BPH demonstrated an increase in the stromal compartment, indicating that BPH was mainly a stromal disease $(44,96-98)$. However, these studies were limited by very low patient numbers and the use of prostate chips from TURP surgeries. The type of prostate surgery for BPH/LUTS skews analysis of phenotypes because TURP harvests mostly peri-urethral smooth muscle while open or robotic simple prostatectomies preserve the whole transition zone as a contiguous piece $(18,99,100)$. Regional phenotypes are easier to observe in whole mount sections from simple prostatectomy specimens than from TURP chips (Figure 3). Because specific phenotypes can be regional, a random chip of TURP tissue may not represent the pathogenic phenotype contributing to prostate enlargement or LUTS. Eventually, we will have to determine the most important cell type(s) contributing to LUTS for an individual patient and have a tailored therapeutic solution. This may involve novel imaging modalities, urinary or tissue biomarkers in conjunction with objective clinical measurements (e.g. PSA, uroflow, etc).

Phenotypic heterogeneity has likely produced too much noise to elucidate the cellular and molecular mechanisms of the different types of benign growth. Pathologists described a 
morphological progression in BPH typified by diffuse growth early, followed by the emergence of small epithelial and stromal nodules in prostates over 50 grams and eventually dilated cystic glands with very little stroma in very large prostates (17-19). These regions were termed 'nodular' and 'inter-nodular'. An example of adjacent BPH nodule and internodule regions from an intact simple prostatectomy specimen is shown in Figure 3C.

Finally, the diverse composition of epithelia, stroma and leukocytes in a multicellular solid organ like the prostate makes elucidating the cellular and molecular mechanisms driving prostatic enlargement even more confounding because the leukocyte signal contaminates a whole tissue analysis of RNA or protein. For example, Figure 2B demonstrates by flow cytometry that $\mathrm{CD} 45^{+}$leukocytes can account for up to a fourth of the total cells in the prostate. In fact, our previous molecular analysis of patients with large prostate volumes undergoing surgery for unmitigated symptoms demonstrated an enrichment of AP-1 transcription factors (101) similar to other studies attempting to determine the molecular progression of BPH based on increasing prostate volume (102). Cell type-specific changes are lost with this approach. As an example of how our group is attempting to deal with cellular heterogeneity, we recently showed that AR expression is decreased with increasing prostate volume, but only in isolated luminal epithelia (103). Stromal AR slightly increased with prostate volume, which is why AR looked unchanged in our previous whole tissue molecular signature. Furthermore, the tissue used for most BPH studies comes from TURP or laser ablation surgery, which creates relatively small pieces of cauterized tissue, abrogating the ability to go back to tissue blocks to study regional phenotypes in the intact prostate gland (see Figure 3). In summary, unique surgical techniques and phenotypic heterogeneity confound our understanding of the pathogeneses of prostatic enlargement. A better experimental design is needed to decipher the molecular mechanisms underlying the various pathological phenotypes in $\mathrm{BPH}$.

\section{Histopathology of benign prostatic hyperplasia}

A histological analysis of BPH nodules show either predominant glandular hyperplasia, or less commonly predominant stromal hyperplasia. The vast majority of BPH nodules encountered are glandular nodules mixed with a myomatous component.

On gross examination, the hyperplastic prostate is enlarged with multiple nodules, mostly located in the transition zone/periurethral region. Most BPH nodules are tan-white to gray, variably sized firm or soft nodules. Predominantly glandular nodules can appear spongy with fluid extrusion from cut surface. It is difficult to distinguish BPH nodules from cancer by gross examination alone; the latter tend to be yellowish-white and firm, and commonly located in the peripheral zone.

Microscopically, BPH nodules have a nodular and circumscribed, but unencapsulated appearance. Hyperplastic glands are tightly clustered and show papillary budding, infoldings and cystic dilatation (Figs. $4 \& 6 \mathrm{D}$ ). Some studies have documented an increase in both total area and luminal area of acini in BPH, but no increase in actual number of acini (104), versus control prostates. Degenerative changes such as calcification, infarction and squamous metaplasia can occur secondarily. Usual type glandular BPH nodules show a 
single basal cell epithelial layer and overlying columnar secretory epithelium, as in the nonhyperplastic prostate. The basal cell hyperplasia variant of BPH shows expansion of the basal cell layer and is easily identified by morphology. This basal cell proliferation may completely replace existing glands forming solid nests of $\mathrm{BCH}$, or may be incomplete with remnants of luminal secretory cells. Cytological features of acinar cells in BPH are usually unremarkable with regular sized nuclei and open chromatin, similar to normal prostatic glands, and without evidence of prominent nucleoli, nuclear enlargement/hyperchromasia or other atypical features that characterize cancer glands.

Purely stromal BPH nodules are seen less commonly than predominantly glandular nodules and are smaller in size. They are usually well circumscribed but without an obvious capsule. The nodules are composed of bland appearing spindle cells of varying cellularity in a sometimes myxoid background, with abundant interspersed small blood vessels and lacking any glandular elements (Figs. 4 \& 6D). The smooth muscle component in stromal nodules typically increases with increasing size of the nodules. The histomorphologic differential diagnoses of stromal nodules include stromal tumor of uncertain malignant potential (STUMP) (possible nuclear atypia, absence of vessels), leiomyoma (more cellular, absence of vessels and presence of capsule), among other entities.

All subtypes of BPH show increased presence of chronic inflammatory cells, usually CD3+ T-cells, in the hyperplastic nodules (105). Other less common histologic BPH variants, that may on occasion mimic cancer, include post-atrophic hyperplasia (atrophic acini with proliferative, dilated and distorted glands), cribriform hyperplasia (crowded, cribriform glands with clear cytoplasm), sclerosing adenosis (dense spindle cell component, hyaline sheath around glands) and atypical adenomatous hyperplasia (crowded small glands, may show mild nuclear atypia). Challenging diagnostic cases can be resolved by immunohistochemical staining for basal cells, the presence of which identifies these glands as benign.

Some morphologic features of BPH nodules such as papillary infoldings and cystic changes can be appreciated on needle biopsy specimens. But since complete nodules are typically not visualized on narrow needle cores, a BPH diagnosis is usually not made, especially if there is no clinical history of LUTS. About $10 \%$ of TURP and simple prostatectomy specimens received for BPH show presence of incidental prostate cancer, usually Gleason grade $3+3$ or lower, and occupying $5 \%$ or lesser of examined prostate tissue.

\section{Experimental design in human BPH research}

A wide range of potential etiological factors have been implicated in BPH/LUTS progression. These have traditionally included variables such as hormones (106), stem cells (107), growth factors (108), fibrosis (109), autoimmunity (110) and chronic inflammation (111). Each of these components can independently characterize an individual's disease etiology, but a synthesis of interacting components has only recently been suggested (112). It is unlikely that a common molecular mechanism of progression characterizes the majority of patients; more likely, various cellular processes drive distinct phenotypes that require patient-specific treatments. Given the histological heterogeneity of the hyperplastic prostate, 
the study of these hypotheses at the molecular level has been hampered by the difficult access to a sufficient number of human tissues with clinical information to separate patients into histological categories.

The fact that needle biopsies have proven ineffective for the histological diagnosis of BPH (113) and therefore excluded from standard clinical practice has prohibited the study of pathologic progression in an individual patient. The only source of longitudinal tissue samples from individual patients comes from a few clinical trials where biopsies were performed at the beginning and end of the trial, but these tissues are not readily available $(114,115)$. Accordingly, a mechanistic understanding and experimental testing of potentially pathogenic molecular factors driving benign growth or therapeutic resistance has only been studied by a prospective grouping of cohorts by either indication of surgery (e.g. 'control' transition zone from age-matched prostate or bladder cancer patients $v s$. transition zone from BPH/LUTS patients $(30,101,116)$ ), or indication of severity (e.g., prostate volume (102), SRD5A2 expression (117), etc). These types of studies are often used when specimens from randomized trials are not accessible and do not prove causation; however, potentially important associations can be drawn after properly controlling for covariates. Optimally, future clinical studies should be designed to track an individual's clinical progression with imaging and clinical data while providing tissue, blood and urine samples at the beginning and end of a multi-year study to fully correlate molecular, cellular and clinical changes of each patient over time.

The different methodologies of retrospectively analyzing randomized samples from clinical trials versus prospectively grouping patients from the clinic into surgical cohorts have contributed in individual ways. Much of the information derived from randomized longitudinal studies of BPH progression is focused on effectors of disease outcome such as comorbidities, hormone levels, and inflammation with further information derived from immunohistochemical analysis of tissue blocks $(10,118)$. Alternatively, studies where molecular profiles are generated from fresh tissue collected from prospectively grouped patient cohorts based on indication of surgery allow for retrospective multivariate correlations to be drawn with pathological and clinical profiles $(30,101,102,116,119)$. Essentially, correlations can be drawn between a specific molecular profile and clinical variables such as age, symptom score, voiding profile, prostate volume, medication, and indication or severity of comorbid conditions.

The optimal 'control' tissue for determining the molecular mechanisms driving prostate growth would be age-matched, small volume transition zone from 'healthy' patients, e.g. without prostate or bladder cancer. Access to this tissue is impractically rare and hard to procure fresh for cell type-specific studies. Many studies have avoided this problem by only analyzing BPH tissue on the basis of objective parameters such as prostate volume (102) (analyzing by a subjective symptom score is inherently problematic). Alternatively, small volume prostate tissue from younger men could be used as a control. This source of tissue is also extremely hard to access. Moreover, given that BPH/LUTS is an age-related condition, a similarly aged population would be beneficial to eliminate normal age-related changes not related to prostate growth. Furthermore, age-matched autopsy specimens could be used with the caveat that tissue procurement could take hours or days, potentially decreasing the 
quality of the tissues. To side-step issues with access to control transition zone tissue, many groups will use transition zone tissue from patients undergoing prostatectomy for tumors that are predominantly in the peripheral zone or cystoprostatectomy tissue from patients with bladder cancer. Using these tissues as controls presumes the lack of a field effect.

About $30 \%$ percent of prostate tumors are found in the transition zone and these can be removed from the control cohort retrospectively after pathological review. Results from BPH tissue arrays that have indiscriminately made use of both transition zone and peripheral zone tissue from prostatectomy patients with cancer as controls for symptomatic patient tissue must be analyzed with this in mind $(30,120)$. Most men undergoing surgery for peripheral zone tumors also have transition zone hyperplasia and have even been on medication for lower urinary tract symptoms. It is unclear whether prostate volumes and high symptom scores are more related to the peripheral zone cancer or transition zone hyperplasia without a direct measurement of transition zone volume by MRI. In addition, our experience is that men in this 'Incidental BPH' category are younger on average and could just be earlier in their benign disease progression. Accordingly, it is important to statistically control for these covariates when comparing the molecular profiles from different transition zone tissue cohorts (101).

Eventually, it will be important to combine what can be learned about the incidence of BPH/ LUTS and the association of comorbidities from randomized population studies with the correlative molecular data generated from the analyses of prospective surgical or clinical cohorts. This will have to be accomplished through the coordination of prospective tissue collection from future randomized clinical trials. While we wait for matched samples from longitudinal clinical trials or proper small volume control transition zone tissue from young and old non-diseased men, what can we learn about the molecular and cellular pathogenesis of BPH using only diseased tissue from patients undergoing TURP or simple prostatectomy for management of their BPH/LUTS?

\section{Towards personalized medicine: molecular pathogenesis of distinct phenotypes and their diagnosis in the clinic}

\section{Molecular pathogenesis of distinct BPH phenotypes}

There are a number of questions regarding the diverse cellular pathogeneses of BPH that can be answered with a sufficient, if not imperfect, cohort of diseased prostate specimens; but this requires a categorization of phenotypes in order to generate phenotype-specific signatures. There are three predominant phenotypes observed in BPH specimens: basal cell hyperplasia, stromal hyperplasia, and glandular hyperplasia. Some specimens are composed of a single glandular or stromal phenotype, and some specimens are mixed (23). This phenotypic heterogeneity is best displayed by whole mounting coronal sections on large glass slides (Figure 4). The question is how to generate clean signatures of the pathogenic cell type in each phenotype without the noise of all the other contaminating cell types present in the specimen. One approach is to digest these fresh specimens into single cells and isolate specific cell types by flow cytometry, but this requires the ability to macrodissect out specific phenotypes in fresh tissue based on gross morphological characteristics. Figure 
5 demonstrates the feasibility of this approach using simple prostatectomy specimens, and illustrates the variety of morphological and cellular forms composing individual patients with benign hyperplasia.

The least common phenotype observed in hyperplastic prostate specimens is basal cell hyperplasia $(\mathrm{BCH})($ Figure 5A-D). The incidence of $\mathrm{BCH}$ in the human prostate ranges from $8-10 \%$ of prostatectomy specimens and can be distinguished from basal cell carcinoma (BCC) based on nuclear morphology and proliferation index (121). The etiology of BCH is unclear. However, the observation that $\mathrm{BCH}$ is associated with 5ARI treatment, estrogen treatment and chronic lymphocytic inflammation could suggest a role for abnormal hormone levels as an initiating event $(30,122,123)$.

Stromal nodules are the next most common phenotype of BPH (Figure 5E-H), but can be composed of many cell types including immature mesenchyme, fibroblasts, and smooth muscle $(23,52-54,124)$. Stromal nodules are densely packed with T helper cell and B lymphocytes, but do not display proliferative markers (52). If we take stromal hyperplasia to represent a distinct cellular etiology from glandular hyperplasia (even though both phenotypes can be present in an individual specimen - Figure 4C), one could ask whether the cell of origin for various hyperplastic stromal phenotypes are an expansion or dedifferentiation of indigenous cells or whether they are mesenchymal stem cells recruited from outside the prostate (109). There is some evidence that bone marrow-derived mesenchymal stem cells can home to the prostate in mice (125), but the extent of this recruitment or its contribution to hyperplasia in the prostate is equivocal due to the inability to trace the origins of cellular lineage in humans. Nonetheless, there is evidence of mesenchymal stem cells residing in the human prostate that can be induced to multiple lineages ex vivo $(84,126)$. More lineage tracing in experimental models of prostatic inflammation and fibrosis is needed to clarify the origins of stromal hyperplasia.

Data from stromal BPH nodules show a highly enriched population of CD34+ fibroblasts $(52,53,124,127)$, but it is unclear whether these are derived from CD34+/CD31+ perivascular cells, a de-differentiation of resident smooth muscle or fibroblast, or a recruitment of bone marrow mesenchymal stem cells. In addition, stromal hyperplasia could involve the expansion/recruitment of a CD34+ mesenchymal cell type as found in other organs such as the intestine (128). Lineage tracing of cells contributing to kidney fibrosis in a mouse demonstrates a Gli1+/Pdgfr $\beta+$ perivascular cell of origin for myofibroblasts (129). A more thorough characterization of the various populations in prostate stromal hyperplasia is needed based on the variety of stromal phenotypes described by pathologists (124).

Finally, glandular nodules are the most common form of hyperplasia to emerge with increasing prostate volume (18) (Figure 5I-L). Glandular nodules are characterized by a dense aggregation of glandular epithelium with sparse stroma and may be distinguished from stromal hyperplasia by magnetic resonance imaging (MRI) as covered in the next section (130). The areas outside the confined glandular nodule are described as 'internodular', and display a significantly higher proportion of fibromuscular stroma (18) (Figure 3C). We have yet to develop an understanding of the molecular and cellular drivers of glandular nodule formation in part, because of the fundamental problems with experimental 
design mentioned previously. If the glandular nodule has a distinct molecular pathogenesis from the inter-nodular regions surrounding it, then randomly analyzing pieces of tissue from such phenotypically heterogeneous specimens will fail to provide the actionable molecular targets needed for developing treatments. Furthermore, given the known role of stromalepithelial interactions in glandular morphogenesis during development (131) and the suggestion by pathologists that BPH is an 'embryonic reawakening' (23), how can it be determined whether a specific cell type within these nodules is driving nodule morphogenesis? This may require the macrodissection of nodular phenotypes in fresh tissue prior to cellular and molecular analyses and a suitable experimental model such as xenografting to study specific phenotypes and their response to novel therapies. Examples of the cellular composition of macrodissected stromal and glandular nodules are shown in Figure 5.

\section{Xenografts for the study of BPH phenotypes}

In order to understand BPH progression from molecular, cell biological and therapeutic viewpoints, it is useful to take the tissue of interest and graft it into an animal host that is easy to manipulate. Most commonly these hosts are immunocompromised rodents including mice and rats. Some of the benefits of xenografting into rodents include: ease of use, decreased costs, and genetic or pharmacological control of the local or systemic environment. Although it is possible to xenograft any BPH tissue (e.g. various species and models of BPH), human BPH specimens are the most commonly used. In this regard, xenografts are particularly well suited for assessing pharmacologic agents on BPH growth. To this end, in the future, BPH xenografts may be used in precision medicine, where a given patients' tissues can be assessed for therapeutic efficacy.

BPH tissue can be grafted into multiple organ sites within immunocompromised hosts. Each site has advantages and disadvantages, which individual investigators have exploited to assess BPH. Advantages include ease of use, relevant histology, and take rate efficiency. Three common sites are generally used for BPH xenografts: subcutaneous, renal capsule, and orthotopic. Previous studies have assessed the take rate efficiency and tissue histological features of these three sites for human prostate tissues including BPH (132). Although the subcutaneous site is perhaps the easiest to graft into, it yields tissues that histologically were less like the original tissue collected, suggesting the microenvironment or other factors were different. This outcome may make interpretation of results difficult. Moreover, the take rate of the subcutaneous site was lower (58\%) than in orthotopic (72\%) and renal (93\%) sites. These data support the use of renal or orthotopic grafts sites for BPH studies. However, a common argument against the utilization of the renal and orthotopic sites is the expertise required to perform such studies. However, this has been diminished because the renal site methods have been streamlined and are now often used (132-134). In the end, the user will identify the appropriate site to engraft BPH specimens to assess parameters important for individual studies.

Besides xenografting whole pieces of BPH tissue, heterotypic tissue recombination xenografting has been used to study the interactions between inductive fetal rodent urogenital mesenchyme and human prostate epithelial organoids (135). Contemporary 
studies showed that urogenital mesenchyme could drive differentiation of pseudostratified human prostate glands from other endodermally-derived epithelia including bladder and urethra as well $(136,137)$. More recently, tissue recombination xenografting has been used to identify stem and progenitor epithelia capable of regenerating prostate glandular structures (138-140). In this technique, specific epithelial subtypes are isolated by flow cytometry with cell surface markers. If, for instance, there are specific epithelial cell types represented in glandular prostate nodules or resistant to 5ARI treatment, tissue recombination xenografting would be a useful tool for characterizing the regenerative potential of these populations constituting specific histopathological phenotypes.

In addition to demonstrating the powerful inductivity of urogenital mesenchyme, Hayward and Cunha's original study (135) also showed that human epithelium induced a human-like smooth muscle patterning of the rodent mesenchyme, suggesting reciprocal feedback. It would be interesting to note whether the original histopathological phenotype of the glandular nodule (high epithelial to stromal ratio) would be recapitulated after induction by urogenital mesenchyme, which would suggest that the epithelium is dominating the patterning. This would also provide a robust model system to test the effects of hormones or drugs on the pathogenic phenotype. Alternatively, the inductive mesenchyme could be capable of reprogramming nodular epithelium and restoring the stromal to epithelial ratio. Using kidney capsule xenografting to test the regenerative capacity of various stromal cell populations extracted from patients with stromal hyperplasia is sorely underdeveloped and could help to identify the pathogenic cell types responsible for that phenotype as well.

\section{Diagnosis of distinct phenotypes in the clinic}

With so many morphological varieties, and so many cell types within each heterogeneous phenotype, how do we begin to parse the contribution of individual cell types to basal, stromal, and glandular hyperplasia? Clearly, a more comprehensive approach to dealing with phenotypic and cellular heterogeneity is required in order to provide personalized therapeutic options moving forward. Our group has recently begun to attempt to deconstruct this pathologic heterogeneity by separating histological phenotypes and analyzing cell typespecific molecular profiles within each phenotypic category. Using a combination of radiology, pathology, and cell type-specific analyses driven by flow cytometry and single cell sequencing, it may be possible to better define the molecular pathogenesis of individual phenotypes. To effectively tailor this information to improve clinical outcomes through precision medicine, development of biomarkers or imaging modalities that are superior to standard analysis of BPH severity, will be needed.

One of the areas that is rapidly emerging as a potentially useful clinical and research tool for stratifying BPH patients is diagnostic imaging (141). Typically, once benign prostatic hyperplasia is suspected as a likely cause of LUTS, prostate volume is measured by ultrasound due to its cost-effectiveness. CT is inferior to both ultrasound and MRI in its ability to discriminate prostate zonal anatomy, providing limited diagnostic value for patients with BPH. Moreover, both MRI and ultrasound provide the most accurate estimation of prostate volume. Prostate volume provides a useful metric for the urologist to 
judge BPH severity and certain features on MRI help to distinguish BPH from prostate cancer.

Radiologists have described a lobar classification of BPH based on an understanding of the many anatomical forms the prostate can assume in individual patients $(142,143)$. This classification system was predicated on a comprehensive gross pathological description of 222 post-mortem cases of BPH performed by Randall, et al in 1931 (144). MRI has successfully been used to discriminate stromal vs. glandular hyperplasia, and even predict clinical outcomes after medical treatment $(16,130,145)$. We recently developed a system to correlate MRI with pathology using imaging-derived, 3D-printed whole-mount molds for radical prostatectomy specimens from prostate cancer patients (146). We are building on this experience with simple prostatectomy specimens for BPH patients, which demonstrates our ability to discriminate between glandular and stromal phenotypes even within the same patient. Figure 6 demonstrates our approach to linking the features observed on MRI with the phenotypes observed grossly. First, we collect urine, blood, and relevant clinical data that eventually may be correlated with disease severity or subtypes (Figure 6A). At the time of surgery, two fresh coronal serial sections of tissue are collected (Figure 6C): the first section is used for generating a whole mount image to register with MR images (Figure 6B, D), and the second serial section is used for macrodissection into discrete phenotypes that can then be digested into individual cells for analysis by flow cytometry (Figure 6E) or single cell sequencing. This approach will allow us to gain a better understanding of the specific cell types that comprise each phenotype along with their diagnostic signature, and hopefully lead to novel molecular targets for each phenotype. As MRI may not be practical in every clinic, our goal is to eventually develop urinary or blood biomarkers of phenotypic subtypes to aid the clinician in choosing the optimal treatment.

\section{Conclusion: clinical management of distinct BPH pathogeneses}

Despite the advent of medical therapy in the 1990s, over 250,000 elderly men each year undergo surgical intervention for unmitigated symptoms (147), highlighting the underlying complexity of the disease(s) and the potential need for personalized medicine (148). There are currently no reliable biomarkers of specific phenotypes or progression, no animal models that encompass and recapitulate human symptomatic progression, and little understanding of either the effects of specific comorbidities or the response to therapy. Accordingly, goals for the treatment of BPH/LUTS should be to 1) identify causative molecular pathways, likely involved in a specific BPH phenotype, for the rational design or repurpose of targeted therapeutics, 2) identify predictive prostatic phenotypes and biomarkers to prevent disease progression with early intervention, and 3) identify the mechanisms of resistance to current therapies. To meet these goals, we need a deeper understanding of the cellular and molecular response of the prostate to comorbidities, inflammation, and medical therapy, and this must be driven by a coordinated tissue and clinical data collection effort. This effort should include the collection of fresh non-diseased prostate specimens from young and old donors to establish baseline molecular and cellular profiles. It is also important to consider that studying the effects of hormones and comorbidities will require the prospective collection and processing of blood tests such as Hemoglobin A1c must be performed on fresh blood. If urinary biomarkers are to play a role in the diagnosis of $\mathrm{BPH}$ phenotypes, urine must also be 
prospectively collected. This comprehensive approach to deconstructing lower urinary tract diseases will be essential for fulfilling the NIDDK Prostate Research Plan Priority Recommendation to develop research efforts for phenotype-specific therapies for LUTS, $B P H$, and prostatitis based on respective pathological criteria for enhancing efficacy, avoiding treatment failures, and improving cost effectiveness (24).

\section{Acknowledgments}

The authors thank the families of organ donors at the Southwest Transplant Alliance for their dedication to basic science research. This work was supported by the NIH/NIDDK (DK098277, DK110497 to DWS, and U54DK104310 to WAR).

\section{Abbreviations}

$\begin{array}{ll}\text { AR } & \text { Androgen Receptor } \\ \text { BPH } & \text { Benign Prostatic Hyperplasia } \\ \text { LUTS } & \text { Lower Urinary Tract Symptoms } \\ \text { PVR } & \text { Post-Void Residual } \\ \text { AUR } & \text { Acute Urinary Retention } \\ \text { AUASS } & \text { American Urological Association Symptom Score } \\ \text { PSA } & \text { Prostate Specific Antigen } \\ \text { 5ARI } & \text { 5 Alpha Reductase Inhibitor } \\ \text { DHT } & \text { Dihydrotestosterone } \\ \text { MTOPS } & \text { Medical Therapy of Prostate Symptoms } \\ \text { TURP } & \text { Transurethral Resection of the Prostate } \\ \text { BCH } & \text { Basal Cell Hyperplasia } \\ \text { MRI } & \text { Magnetic Resonance Imaging } \\ \text { PZ } & \text { Peripheral Zone } \\ \text { TZ } & \text { Transition Zone }\end{array}$

\section{References}

1. Platz EA, et al. Incidence and progression of lower urinary tract symptoms in a large prospective cohort of United States men. J Urol. 2012; 188(2):496-501. [PubMed: 22704110]

2. CDC. The State of Aging and Health in America 2013. 2013.

3. Jacobsen SJ, et al. New diagnostic and treatment guidelines for benign prostatic hyperplasia. Potential impact in the United States. Arch Intern Med. 1995; 155(5):477-81. [PubMed: 7532392]

4. Saigal CS, Joyce G. Economic costs of benign prostatic hyperplasia in the private sector. J Urol. 2005; 173(4):1309-13. [PubMed: 15758787] 
5. Parsons JK, et al. Metabolic factors associated with benign prostatic hyperplasia. J Clin Endocrinol Metab. 2006; 91(7):2562-8. [PubMed: 16608892]

6. Mozumdar A, Liguori G. Persistent increase of prevalence of metabolic syndrome among U.S. adults: NHANES III to NHANES 1999-2006. Diabetes Care. 2011; 34(1):216-9. [PubMed: 20889854]

7. McNeal JE. The zonal anatomy of the prostate. Prostate. 1981; 2(1):35-49. [PubMed: 7279811]

8. Roehrborn CG, et al. Serum prostate specific antigen is a strong predictor of future prostate growth in men with benign prostatic hyperplasia. PROSCAR long-term efficacy and safety study. J Urol. 2000; 163(1):13-20. [PubMed: 10604304]

9. Roehrborn CG. Pathology of benign prostatic hyperplasia. Int J Impot Res. 2008; 20(Suppl 3):S118.

10. Roehrborn CG. Definition of at-risk patients: baseline variables. BJU Int. 2006; 97(Suppl 2):7-11. discussion 21-2. [PubMed: 16507046]

11. Emberton M. Definition of at-risk patients: dynamic variables. BJU Int. 2006; 97(Suppl 2):12-5. discussion 21-2. [PubMed: 16507047]

12. Parsons JK, Kashefi C. Physical activity, benign prostatic hyperplasia, and lower urinary tract symptoms. Eur Urol. 2008; 53(6):1228-35. [PubMed: 18358592]

13. McConnell JD, et al. The long-term effect of doxazosin, finasteride, and combination therapy on the clinical progression of benign prostatic hyperplasia. N Engl J Med. 2003; 349(25):2387-98. [PubMed: 14681504]

14. Roehrborn CG, et al. Clinical outcomes after combined therapy with dutasteride plus tamsulosin or either monotherapy in men with benign prostatic hyperplasia (BPH) by baseline characteristics: 4year results from the randomized, double-blind Combination of Avodart and Tamsulosin (CombAT) trial. BJU Int. 2011; 107(6):946-54. [PubMed: 21332630]

15. Shapiro E, Hartanto V, Lepor H. The response to alpha blockade in benign prostatic hyperplasia is related to the percent area density of prostate smooth muscle. Prostate. 1992; 21(4):297-307. [PubMed: 1281322]

16. Isen K, et al. Magnetic resonance imaging and morphometric histologic analysis of prostate tissue composition in predicting the clinical outcome of terazosin therapy in benign prostatic hyperplasia. Int J Urol. 2001; 8(2):42-8. [PubMed: 11240824]

17. Schuster GA, Schuster TG. The relative amount of epithelium, muscle, connective tissue and lumen in prostatic hyperplasia as a function of the mass of tissue resected. J Urol. 1999; 161(4): 1168-73. [PubMed: 10081863]

18. Price H, McNeal JE, Stamey TA. Evolving patterns of tissue composition in benign prostatic hyperplasia as a function of specimen size. Hum Pathol. 1990; 21(6):578-85. [PubMed: 2351388]

19. Franks LM. Benign nodular hyperplasia of the prostate; a review. Ann R Coll Surg Engl. 1953; 14(2):92-106. [PubMed: 13125240]

20. Gormley GJ, et al. The effect of finasteride in men with benign prostatic hyperplasia. The Finasteride Study Group. N Engl J Med. 1992; 327(17):1185-91. [PubMed: 1383816]

21. Wei JT, Calhoun E, Jacobsen SJ. Urologic diseases in america project: benign prostatic hyperplasia. J Urol. 2008; 179(5 Suppl):S75-80. [PubMed: 18405761]

22. Guneyli S, et al. Magnetic resonance imaging of benign prostatic hyperplasia. Diagn Interv Radiol. 2016; 22(3):215-9. [PubMed: 27015442]

23. McNeal JE. Origin and evolution of benign prostatic enlargement. Invest Urol. 1978; 15(4):340-5. [PubMed: 75197]

24. NIDDK. NIDDK Prostate Research Strategic Plan. 2008. https://www.niddk.nih.gov/about-niddk/ strategic-plans-reports/Pages/niddk-prostate-research-strategic-plan.aspx

25. Lepor H, Kazzazi A, Djavan B. alpha-Blockers for benign prostatic hyperplasia: the new era. Curr Opin Urol. 2012; 22(1):7-15. [PubMed: 22080875]

26. Lepor $\mathrm{H}$, et al. A randomized, placebo-controlled multicenter study of the efficacy and safety of terazosin in the treatment of benign prostatic hyperplasia. J Urol. 1992; 148(5):1467-74.

[PubMed: 1279214] 
27. Pelletier G, et al. Localization by in situ hybridization of steroid 5alpha-reductase isozyme gene expression in the human prostate and preputial skin. J Urol. 1998; 160(2):577-82. [PubMed: 9679931]

28. Span PN, et al. Selectivity of finasteride as an in vivo inhibitor of 5alpha-reductase isozyme enzymatic activity in the human prostate. J Urol. 1999; 161(1):332-7. [PubMed: 10037433]

29. Andriole GL, et al. Effect of the dual 5alpha-reductase inhibitor dutasteride on markers of tumor regression in prostate cancer. J Urol. 2004; 172(3):915-9. [PubMed: 15310997]

30. Bauman TM, et al. Finasteride treatment alters tissue specific androgen receptor expression in prostate tissues. Prostate. 2014; 74(9):923-32. [PubMed: 24789081]

31. Group TFS. Finasteride (MK-906) in the treatment of benign prostatic hyperplasia. The Finasteride Study Group. Prostate. 1993; 22(4):291-9. [PubMed: 7684524]

32. Thigpen AE, et al. Tissue distribution and ontogeny of steroid 5 alpha-reductase isozyme expression. Journal of Clinical Investigation. 1993; 92(2):903-910. [PubMed: 7688765]

33. Russell DW, WJD. Steroid 5alpha-reductase: two genes/two enzymes. Annu Rev Biochem. 1994; 63:25. [PubMed: 7979239]

34. Roehrborn CG, et al. The effects of combination therapy with dutasteride and tamsulosin on clinical outcomes in men with symptomatic benign prostatic hyperplasia: 4-year results from the CombAT study. Eur Urol. 2010; 57(1):123-31. [PubMed: 19825505]

35. Kirby RS, et al. Efficacy and tolerability of doxazosin and finasteride, alone or in combination, in treatment of symptomatic benign prostatic hyperplasia: the Prospective European Doxazosin and Combination Therapy (PREDICT) trial. Urology. 2003; 61(1):119-26. [PubMed: 12559281]

36. Emberton M, et al. Response to daily $10 \mathrm{mg}$ alfuzosin predicts acute urinary retention and benign prostatic hyperplasia related surgery in men with lower urinary tract symptoms. J Urol. 2006; 176(3):1051-6. [PubMed: 16890690]

37. Boyle P, Gould AL, Roehrborn CG. Prostate volume predicts outcome of treatment of benign prostatic hyperplasia with finasteride: meta-analysis of randomized clinical trials. Urology. 1996; 48(3):398-405. [PubMed: 8804493]

38. Lepor H. Medical treatment of benign prostatic hyperplasia. Rev Urol. 2011; 13(1):20-33. [PubMed: 21826125]

39. Cindolo L, et al. Drug adherence and clinical outcomes for patients under pharmacological therapy for lower urinary tract symptoms related to benign prostatic hyperplasia: population-based cohort study. Eur Urol. 2015; 68(3):418-25. [PubMed: 25465970]

40. Bjerklund, Johansen TE., Baker, TM., Black, LK. Cost-effectiveness of combination therapy for treatment of benign prostatic hyperplasia: a model based on the findings of the Combination of Avodart and Tamsulosin trial. BJU Int. 2012; 109(5):731-8. [PubMed: 21933326]

41. DiSantostefano RL, Biddle AK, Lavelle JP. An evaluation of the economic costs and patientrelated consequences of treatments for benign prostatic hyperplasia. BJU Int. 2006; 97(5):100716. [PubMed: 16542339]

42. Marks LS, et al. Morphometry of the prostate: I. Distribution of tissue components in hyperplastic glands. Urology. 1994; 44(4):486-92. [PubMed: 7524234]

43. Deering RE, et al. Morphometric quantitation of stroma in human benign prostatic hyperplasia. Urology. 1994; 44(1):64-70. [PubMed: 7518983]

44. Rohr HP, Bartsch G. Human benign prostatic hyperplasia: a stromal disease? New perspectives by quantitative morphology. Urology. 1980; 16(6):625-33. [PubMed: 6160671]

45. Fullhase C, et al. Systematic Review of Combination Drug Therapy for Non-neurogenic Male Lower Urinary Tract Symptoms. Eur Urol. 2013; 64(2):228-43. [PubMed: 23375241]

46. Kaplan SA, et al. Add-on fesoterodine for residual storage symptoms suggestive of overactive bladder in men receiving alpha-blocker treatment for lower urinary tract symptoms. BJU Int. 2012; 109(12):1831-40. [PubMed: 21966995]

47. Kaplan SA, et al. Antimuscarinics for treatment of storage lower urinary tract symptoms in men: a systematic review. Int J Clin Pract. 2011

48. Roehrborn CG, et al. Erectile dysfunction and lower urinary tract symptoms associated with benign prostatic hyperplasia (LUTS/BPH) combined responders to tadalafil after 12 weeks of treatment. BJU International. 2016; 118(1):153-160. [PubMed: 26765325] 
49. Chapple CR, et al. Effect of tadalafil on male lower urinary tract symptoms: An integrated analysis of storage and voiding international prostate symptom subscores from four randomised controlled trials. European Urology. 2015; 67(1):114-122. [PubMed: 25301757]

50. Roehrborn CG, et al. Effects of tadalafil once daily on maximum urinary flow rate in men with lower urinary tract symptoms suggestive of benign prostatic hyperplasia. Journal of Urology. 2014; 191(4):1045-1050. [PubMed: 24445278]

51. Dmochowski R, et al. Urodynamic effects of once daily tadalafil in men with lower urinary tract symptoms secondary to clinical benign prostatic hyperplasia: a randomized, placebo controlled 12week clinical trial. J Urol. 2013; 189(1 Suppl):S135-40. [PubMed: 23234619]

52. Bierhoff E, et al. Stromal nodules in benign prostatic hyperplasia. Eur Urol. 1996; 29(3):345-54. [PubMed: 8740022]

53. Bierhoff E, et al. Morphological analogies of fetal prostate stroma and stromal nodules in BPH. Prostate. 1997; 31(4):234-40. [PubMed: 9180933]

54. Hansel DE, et al. Spindle cell lesions of the adult prostate. Mod Pathol. 2007; 20(1):148-58. [PubMed: 17170745]

55. Herawi M, Epstein JI. Specialized stromal tumors of the prostate: a clinicopathologic study of 50 cases. Am J Surg Pathol. 2006; 30(6):694-704. [PubMed: 16723846]

56. Aaron L, Franco OE, Hayward SW. Review of Prostate Anatomy and Embryology and the Etiology of Benign Prostatic Hyperplasia. Urol Clin North Am. 2016; 43(3):279-88. [PubMed: 27476121]

57. Hayward SW, et al. Epithelial development in the rat ventral prostate, anterior prostate and seminal vesicle. Acta Anatomica. 1996; 155:81-93. [PubMed: 8828706]

58. Thomson AA. Role of androgens and fibroblast growth factors in prostatic development. Reproduction. 2001; 121(2):187-95. [PubMed: 11226043]

59. Hayward SW, et al. Stromal development in the ventral prostate, anterior prostate and seminal vesicle of the rat. Acta Anatomica. 1996; 155:94-103. [PubMed: 8828707]

60. Rane JK, et al. Conserved two-step regulatory mechanism of human epithelial differentiation. Stem Cell Reports. 2014; 2(2):180-8. [PubMed: 24527392]

61. van, Leenders GJ., Schalken, JA. Epithelial cell differentiation in the human prostate epithelium: implications for the pathogenesis and therapy of prostate cancer. Crit Rev Oncol Hematol. 2003; 46(Suppl):S3-10. [PubMed: 12850522]

62. Wang Y, et al. Cell differentiation lineage in the prostate. Differentiation. 2001; 68(4-5):270-9. [PubMed: 11776479]

63. Bonkhoff H, Remberger K. Differentiation pathways and histogenetic aspects of normal and abnormal prostatic growth: a stem cell model. Prostate. 1996; 28(2):98-106. [PubMed: 8604398]

64. Shen MM, Abate-Shen C. Molecular genetics of prostate cancer: new prospects for old challenges. Genes Dev. 2010; 24(18):1967-2000. [PubMed: 20844012]

65. Peehl DM, Leung GK, Wong ST. Keratin expression: a measure of phenotypic modulation of human prostatic epithelial cells by growth inhibitory factors. Cell Tissue Res. 1994; 277(1):11-8. [PubMed: 7519968]

66. Zhang D, et al. Stem cell and neurogenic gene-expression profiles link prostate basal cells to aggressive prostate cancer. Nat Commun. 2016; 7:10798. [PubMed: 26924072]

67. Kim W, et al. Clinical effects of discontinuing 5-alpha reductase inhibitor in patients with benign prostatic hyperplasia. Korean J Urol. 2014; 55(1):52-6. [PubMed: 24466398]

68. Stoner E. The clinical effects of a 5 alpha-reductase inhibitor, finasteride, on benign prostatic hyperplasia. The Finasteride Study Group. J Urol. 1992; 147(5):1298-302. [PubMed: 1373779]

69. Blackwood JK, et al. In situ lineage tracking of human prostatic epithelial stem cell fate reveals a common clonal origin for basal and luminal cells. J Pathol. 2011; 225(2):181-8. [PubMed: 21898876]

70. Gaisa NT, et al. Clonal architecture of human prostatic epithelium in benign and malignant conditions. J Pathol. 2011; 225(2):172-80. [PubMed: 21898875]

71. Isaacs JT. Prostate stem cells and benign prostatic hyperplasia. Prostate. 2008; 68(9):1025-34. [PubMed: 18386293] 
72. English HF, Santen RJ, Isaacs JT. Response of glandular versus basal rat ventral prostatic epithelial cells to androgen withdrawal and replacement. Prostate. 1987; 11(3):229-242. [PubMed: 3684783]

73. Shi X, et al. Prostate progenitor cells proliferate in response to castration. Stem Cell Res. 2014; 13(1):154-63. [PubMed: 24905440]

74. Wang X, et al. A luminal epithelial stem cell that is a cell of origin for prostate cancer. Nature. 2009; 461(7263):495-500. [PubMed: 19741607]

75. Wang ZA, Shen MM. Revisiting the concept of cancer stem cells in prostate cancer. Oncogene. 2011; 30(11):1261-71. [PubMed: 21119602]

76. Birnie R, et al. Gene expression profiling of human prostate cancer stem cells reveals a proinflammatory phenotype and the importance of extracellular matrix interactions. Genome Biol. 2008; 9(5):R83. [PubMed: 18492237]

77. van, Leenders GJ., et al. Intermediate cells in human prostate epithelium are enriched in proliferative inflammatory atrophy. Am J Pathol. 2003; 162(5):1529-37. [PubMed: 12707036]

78. Liu X, et al. Low CD38 Identifies Progenitor-like Inflammation-Associated Luminal Cells that Can Initiate Human Prostate Cancer and Predict Poor Outcome. Cell Rep. 2016; 17(10):2596-2606. [PubMed: 27926864]

79. Ousset M, et al. Multipotent and unipotent progenitors contribute to prostate postnatal development. Nat Cell Biol. 2012; 14(11):1131-8. [PubMed: 23064263]

80. Choi N, et al. Adult murine prostate basal and luminal cells are self-sustained lineages that can both serve as targets for prostate cancer initiation. Cancer Cell. 2012; 21(2):253-65. [PubMed: 22340597]

81. Kwon OJ, et al. Prostatic inflammation enhances basal-to-luminal differentiation and accelerates initiation of prostate cancer with a basal cell origin. Proc Natl Acad Sci U S A. 2014; 111(5):E592-600. [PubMed: 24367088]

82. Tang F, et al. mRNA-Seq whole-transcriptome analysis of a single cell. Nat Methods. 2009; 6(5): 377-82. [PubMed: 19349980]

83. Satija R, et al. Spatial reconstruction of single-cell gene expression data. Nat Biotechnol. 2015; 33(5):495-502. [PubMed: 25867923]

84. Lin VK, et al. Prostatic stromal cells derived from benign prostatic hyperplasia specimens possess stem cell like property. Prostate. 2007; 67(12):1265-76. [PubMed: 17597114]

85. Peng YC, et al. Sonic hedgehog signals to multiple prostate stromal stem cells that replenish distinct stromal subtypes during regeneration. Proc Natl Acad Sci U S A. 2013; 110(51):20611-6. [PubMed: 24218555]

86. Wang L, et al. Aberrant Transforming Growth Factor-beta Activation Recruits Mesenchymal Stem Cells During Prostatic Hyperplasia. Stem Cells Transl Med. 2017; 6(2):394-404. [PubMed: 28191756]

87. Yalla SV, et al. Correlation of American Urological Association symptom index with obstructive and nonobstructive prostatism. J Urol. 1995; 153(3 Pt 1):674-9. discussion 679-80. [PubMed: 7532231]

88. Rocco B, et al. Recent advances in the surgical treatment of benign prostatic hyperplasia. Ther Adv Urol. 2011; 3(6):263-72. [PubMed: 22164196]

89. Steiner MS, et al. The chimpanzee as a model of human benign prostatic hyperplasia. J Urol. 1999; 162(4):1454-61. [PubMed: 10492237]

90. McNeal, JE. Relationship of the origin of benign prostatic hypertrophy to prostatic structure of man and other mammals. In: Hinman, FJ., editor. Benign Prostatic Hypertrophy. Springer-Verlag; New York: 1983. p. 152-166.

91. De, Marzo AM., Coffey, DS., Nelson, WG. New concepts in tissue specificity for prostate cancer and benign prostatic hyperplasia. Urology. 1999; 53(3 Suppl 3a):29-39. discussion 39-42. [PubMed: 10094098]

92. Roehrborn CG, et al. Serum prostate-specific antigen and prostate volume predict long-term changes in symptoms and flow rate: results of a four-year, randomized trial comparing finasteride versus placebo. PLESS Study Group. Urology. 1999; 54(4):662-9. [PubMed: 10510925] 
93. Bosch JL, et al. The long-term relationship between a real change in prostate volume and a significant change in lower urinary tract symptom severity in population-based men: the Krimpen study. Eur Urol. 2008; 53(4):819-25. discussion 825-7. [PubMed: 17826889]

94. Hao L, et al. In-Depth Characterization and Validation of Human Urine Metabolomes Reveal Novel Metabolic Signatures of Lower Urinary Tract Symptoms. Sci Rep. 2016; 6:30869. [PubMed: 27502322]

95. Greer T, et al. Custom 4-Plex DiLeu Isobaric Labels Enable Relative Quantification of Urinary Proteins in Men with Lower Urinary Tract Symptoms (LUTS). PLoS One. 2015; 10(8):e0135415. [PubMed: 26267142]

96. Bartsch G, et al. Correlation of biochemical (receptors, endogenous tissue hormones) and quantitative morphologic (stereologic) findings in normal and hyperplastic human prostates. J Urol. 1987; 137(3):559-564. [PubMed: 2434669]

97. Shapiro E, et al. The relative proportion of stromal and epithelial hyperplasia is related to the development of symptomatic benign prostate hyperplasia. J Urol. 1992; 147(5):1293-7. [PubMed: 1373778]

98. Shapiro E, Hartanto V, Lepor H. Quantifying the smooth muscle content of the prostate using double-immunoenzymatic staining and color assisted image analysis. J Urol. 1992; 147:11671170. [PubMed: 1372663]

99. McNeal, J. The anatomic heterogeneity of the prostate. In: Murphy, GP., editor. Progress in clinical and biological research. Alan R. Liss; New York: 1980. p. 149-160.

100. McNeal JE. Prostate Anatomy and BPH Morphogenisis. Prog Clin Biol Res. 1984; 145:27-54. [PubMed: 6201879]

101. Lin-Tsai O, et al. Surgical intervention for symptomatic benign prostatic hyperplasia is correlated with expression of the AP-1 transcription factor network. Prostate. 2014; 74(6):669-79. [PubMed: 24500928]

102. Descazeaud A, et al. BPH gene expression profile associated to prostate gland volume. Diagn Mol Pathol. 2008; 17(4):207-13. [PubMed: 18936709]

103. Zhang B, et al. Non-Cell-Autonomous Regulation of Prostate Epithelial Homeostasis by Androgen Receptor. Mol Cell. 2016

104. Babinski MA, et al. Prostatic epithelial and luminal area in the transition zone acini: morphometric analysis in normal and hyperplastic human prostate. BJU Int. 2003; 92(6):592-6. [PubMed: 14511041]

105. De, Nunzio C., et al. The controversial relationship between benign prostatic hyperplasia and prostate cancer: the role of inflammation. Eur Urol. 2011; 60(1):106-17. [PubMed: 21497433]

106. Nicholson TM, Ricke WA. Androgens and estrogens in benign prostatic hyperplasia: past, present and future. Differentiation. 2011; 82(4-5):184-99. [PubMed: 21620560]

107. McLaren ID, Jerde TJ, Bushman W. Role of interleukins, IGF and stem cells in BPH. Differentiation. 2011; 82(4-5):237-43. [PubMed: 21864972]

108. Schauer IG, Rowley DR. The functional role of reactive stroma in benign prostatic hyperplasia. Differentiation. 2011; 82(4-5):200-10. [PubMed: 21664759]

109. Rodriguez-Nieves JA, Macoska JA. Prostatic fibrosis, lower urinary tract symptoms, and BPH. Nat Rev Urol. 2013; 10(9):546-50. [PubMed: 23857178]

110. Kramer G, Mitteregger D, Marberger M. Is benign prostatic hyperplasia (BPH) an immune inflammatory disease? Eur Urol. 2007; 51(5):1202-16. [PubMed: 17182170]

111. Fibbi B, et al. Chronic inflammation in the pathogenesis of benign prostatic hyperplasia. Int $\mathbf{J}$ Androl. 2010; 33(3):475-88. [PubMed: 19508330]

112. Vignozzi L, et al. Benign prostatic hyperplasia: a new metabolic disease? J Endocrinol Invest. 2014

113. Viglione MP, et al. Should the diagnosis of benign prostatic hyperplasia be made on prostate needle biopsy? Hum Pathol. 2002; 33(8):796-800. [PubMed: 12203211]

114. McConnell JD, et al. The long-term effect of doxazosin, finasteride, and combination therapy on the clinical progression of benign prostatic hyperplasia. N Engl J Med. 2003; 349(25):2387-98. [PubMed: 14681504] 
115. Roehrborn CG, et al. Efficacy and safety of dutasteride in the four-year treatment of men with benign prostatic hyperplasia. Urology. 2004; 63(4):709-15. [PubMed: 15072886]

116. Ma J, et al. Prostatic fibrosis is associated with lower urinary tract symptoms. J Urol. 2012; 188(4):1375-81. [PubMed: 22906651]

117. Bechis SK, et al. Age and Obesity Promote Methylation and Suppression of 5-Alpha Reductase 2Implications for Personalized Therapy in Benign Prostatic Hyperplasia. J Urol. 2015

118. Nickel JC, et al. The relationship between prostate inflammation and lower urinary tract symptoms: examination of baseline data from the REDUCE trial. Eur Urol. 2008; 5(6):1379-84.

119. Robert G, et al. Inflammation in benign prostatic hyperplasia: a 282 patients' immunohistochemical analysis. Prostate. 2009; 69(16):1774-80. [PubMed: 19670242]

120. Nicholson TM, et al. Sex steroid receptor expression and localization in benign prostatic hyperplasia varies with tissue compartment. Differentiation. 2013; 85(4-5):140-9. [PubMed: 23792768]

121. Thorson P, et al. Basal cell hyperplasia in the peripheral zone of the prostate. Mod Pathol. 2003; 16(6):598-606. [PubMed: 12808066]

122. Devaraj LT, Bostwick DG. Atypical basal cell hyperplasia of the prostate. Immunophenotypic profile and proposed classification of basal cell proliferations. Am J Surg Pathol. 1993; 17(7): 645-59. [PubMed: 7686348]

123. Risbridger GP, et al. The metaplastic effects of estrogen on mouse prostate epithelium: proliferation of cells with basal cell phenotype. Endocrinology. 2001; 142(6):2443-50. [PubMed: 11356693]

124. Park H, et al. Stromal nodules in benign prostatic hyperplasia: morphologic and immunohistochemical characteristics. Prostate. 2014; 74(14):1433-43. [PubMed: 25111578]

125. Placencio VR, et al. Bone marrow derived mesenchymal stem cells incorporate into the prostate during regrowth. PLoS One. 2010; 5(9):e12920. [PubMed: 20886110]

126. Brennen WN, Denmeade SR, Isaacs JT. Mesenchymal stem cells as a vector for the inflammatory prostate microenvironment. Endocr Relat Cancer. 2013; 20(5):R269-90. [PubMed: 23975882]

127. San, Martin R., et al. Recruitment of CD34(+) fibroblasts in tumor-associated reactive stroma: the reactive microvasculature hypothesis. Am J Pathol. 2014; 184(6):1860-70. [PubMed: 24713391]

128. Stzepourginski I, et al. CD34+ mesenchymal cells are a major component of the intestinal stem cells niche at homeostasis and after injury. Proc Natl Acad Sci U S A. 2017; 114(4):E506-E513. [PubMed: 28074039]

129. Kramann R, et al. Perivascular Gli1+ progenitors are key contributors to injury-induced organ fibrosis. Cell Stem Cell. 2015; 16(1):51-66. [PubMed: 25465115]

130. Ishida J, et al. Benign prostatic hyperplasia: value of MR imaging for determining histologic type. Radiology. 1994; 190(2):329-31. [PubMed: 7506836]

131. Cunha GR, Lung B. The importance of stroma in morphogenesis and functional activity of urogenital epithelium. In Vitro. 1979; 15(1):50-71. [PubMed: 437808]

132. Wang Y, et al. Development and characterization of efficient xenograft models for benign and malignant human prostate tissue. Prostate. 2005; 64(2):149-159. [PubMed: 15678503]

133. Love HD, et al. Androgen regulated genes in human prostate xenografts in mice: relation to BPH and prostate cancer. PLoS One. 2009; 4(12):e8384. [PubMed: 20027305]

134. Nicholson TM, et al. Renal capsule xenografting and subcutaneous pellet implantation for the evaluation of prostate carcinogenesis and benign prostatic hyperplasia. J Vis Exp. 2013; (78)

135. Hayward SW, et al. Interactions between adult human prostatic epithelium and rat urogenital sinus mesenchyme in a tissue recombination model. Differentiation. 1998; 6(3):131-40.

136. Cunha GR, et al. Epithelial-mesenchymal interactions in prostatic development. I. morphological observations of prostatic induction by urogenital sinus mesenchyme in epithelium of the adult rodent urinary bladder. J Cell Biol. 1983; 96(6):1662-70. [PubMed: 6853597]

137. Boutin EL, Battle E, Cunha GR. The response of female urogenital tract epithelia to mesenchymal inductors is restricted by the germ layer origin of the epithelium: prostatic inductions. Differentiation. 1991; 48(2):99-105. [PubMed: 1773919] 
138. Cunha G, Lung B. The possible influences of temporal factors in androgenic responsiveness of urogenital tissue recombinants from wild-type and androgen-insensitive (Tfm) mice. J Exp Zool. 1978; 205:181-194. [PubMed: 681909]

139. Xin L, et al. In vivo regeneration of murine prostate from dissociated cell populations of postnatal epithelia and urogenital sinus mesenchyme. Proc Natl Acad Sci U S A. 2003

140. Leong KG, et al. Generation of a prostate from a single adult stem cell. Nature. 2008; 456(7223): 804-8. [PubMed: 18946470]

141. Grossfeld GD, Coakley FV. Benign prostatic hyperplasia: clinical overview and value of diagnostic imaging. Radiol Clin North Am. 2000; 38(1):31-47. [PubMed: 10664665]

142. Wasserman NF. Benign prostatic hyperplasia: a review and ultrasound classification. Radiol Clin North Am. 2006; 44(5):689-710. viii. [PubMed: 17030221]

143. Wasserman NF, et al. Use of MRI for Lobar Classification of Benign Prostatic Hyperplasia: Potential Phenotypic Biomarkers for Research on Treatment Strategies. AJR Am J Roentgenol. 2015; 205(3):564-71. [PubMed: 26295642]

144. Randall, A. Surgical pathology of prostatic obstructions. Baltimore, MD: Williams \& Wilkins; 1931.

145. Weijers RE, et al. On the prediction of the histologic composition of benign prostatic hyperplasia based on clinical and MRI parameters. Prostate. 1997; 32(3):179-87. [PubMed: 9254897]

146. Costa DN, et al. Improved Magnetic Resonance Imaging-Pathology Correlation With ImagingDerived, 3D-Printed, Patient-Specific Whole-Mount Molds of the Prostate. Invest Radiol. 2017

147. Wei JT, Calhoun E, Jacobsen SJ. Urologic diseases in America project: benign prostatic hyperplasia. J Urol. 2005; 173(4):1256-61. [PubMed: 15758764]

148. Bechis SK, et al. Personalized medicine for the management of benign prostatic hyperplasia. J Urol. 2014; 192(1):16-23. [PubMed: 24582540] 

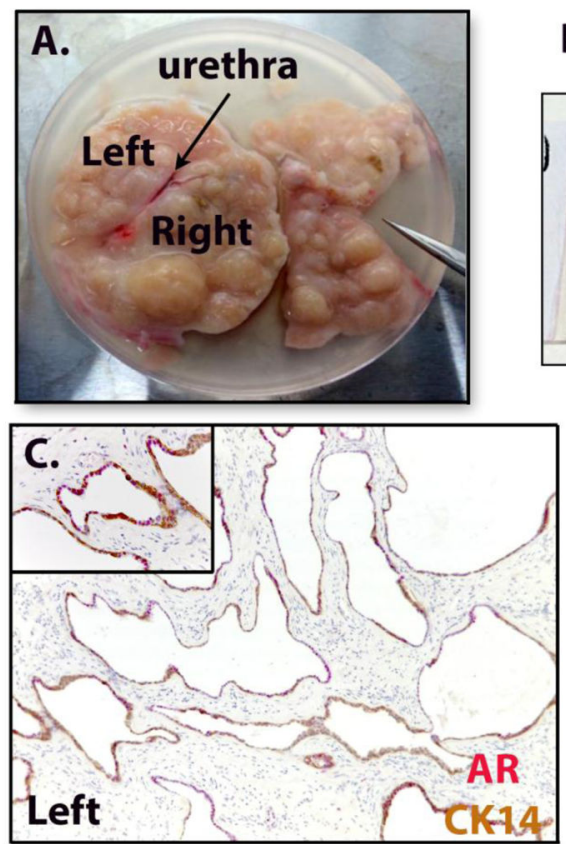

5ARI-responsive
B.
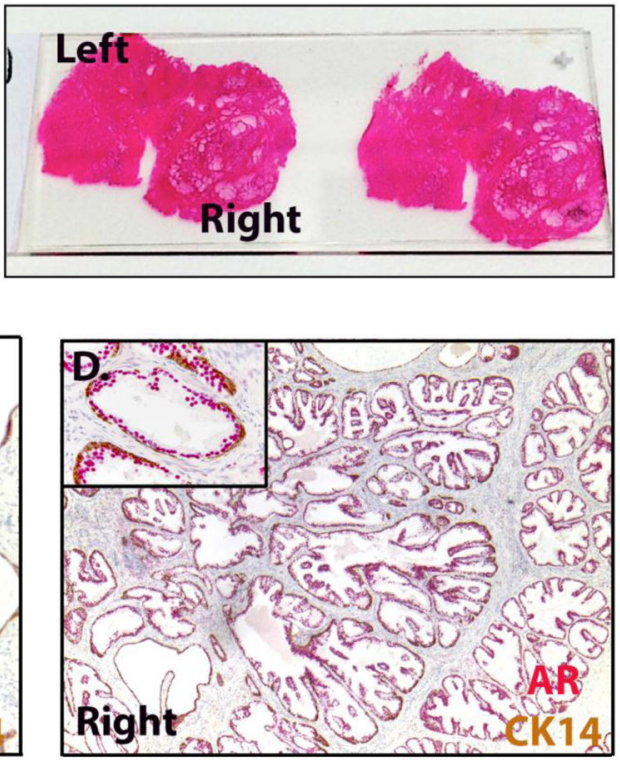

5ARI-resistant

Figure 1. Regional 5ARI resistance in BPH

A, Coronal section of a $130 \mathrm{~g}$ prostate from a $\mathrm{BPH}$ patient on $5 \mathrm{mg} /$ day finasteride for 5 years. B, H\&E stained glass slide with serial sections showing morphological differences between atrophied left side and nodular right side. C, AR/CK14 dual IHC of atrophied left side shows loss of luminal epithelia. D, AR/CK14 IHC of right side shows strong AR staining of luminal epithelia in non-atrophied glands. 

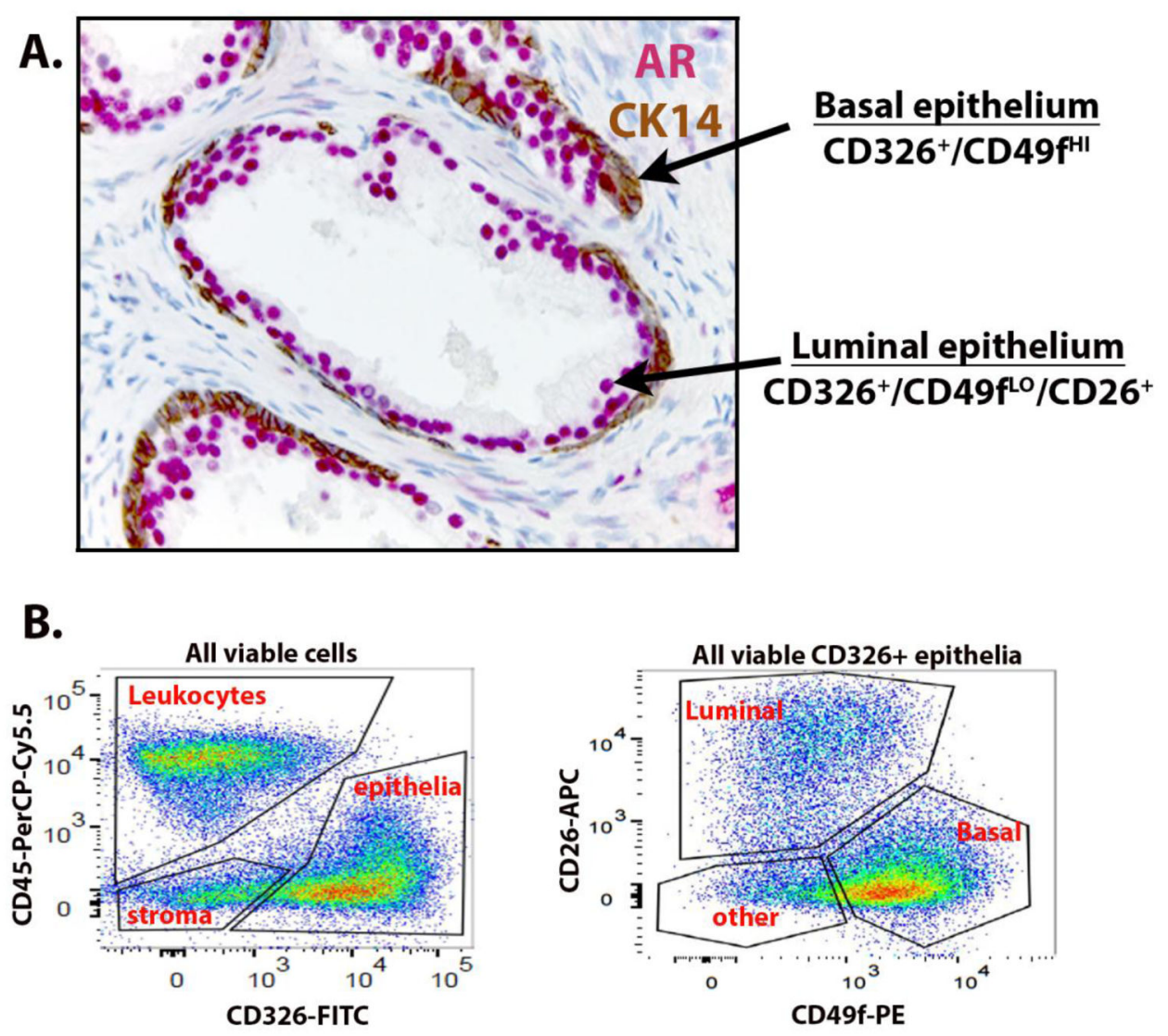

Figure 2. Cell lineage-specific markers identify human prostate cellular lineages

A, Human prostate glands are lined with a layer of $\mathrm{CK} 5 / 14^{+}, \mathrm{p} 63^{+}$cuboidal basal epithelium (brown) and a layer of $\mathrm{CK} 8 / 18^{+}, \mathrm{AR}^{+}, \mathrm{PSA}^{+}$tall columnar, secretory luminal epithelia (red). $\mathbf{B}$, To isolate the major cell types in human prostate by flow cytometry, leukocytes are $\mathrm{CD} 45^{+}$, endothelia are $\mathrm{CD} 45^{-} / \mathrm{CD} 326^{-} / \mathrm{CD} 31^{+}$, basal epithelia are $\mathrm{CD} 45^{-} / \mathrm{CD} 31^{-} / \mathrm{CD} 326^{+} /$ $\mathrm{CD} 49 \mathrm{f}^{\mathrm{HI}} / \mathrm{CD} 26^{-}$, luminal epithelia are $\mathrm{CD} 326^{+} / \mathrm{CD} 49 \mathrm{f}^{\mathrm{LO}} / \mathrm{CD} 26^{+}$, other epithelia are

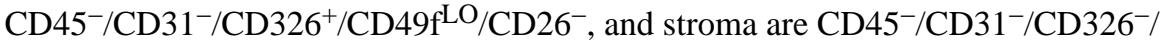
$\mathrm{CD} 49 \mathrm{f}^{\mathrm{LO}} / \mathrm{CD} 26^{-}$. 

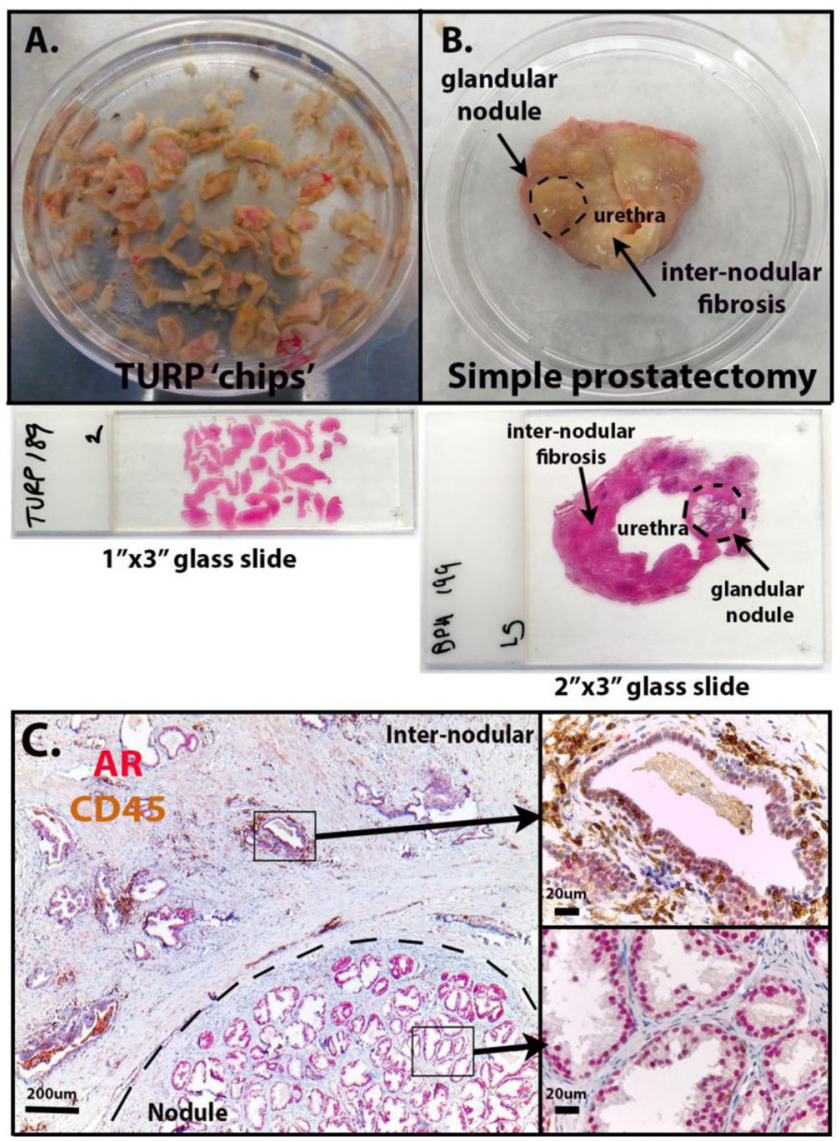

Figure 3. Comparison of BPH surgeries

A, With TURP, a resectoscope is inserted into the penis up to the prostate where 'chips' of prostate tissue are carved off and pushed into the bladder for later withdrawal. Because of the risk of bleeding, simultaneous cauterization is performed. Unfortunately, this does severe damage to the tissue, resulting in poor cell viability. Regional histological phenotypes are also lost as shown on the $1^{\prime \prime} \times 3^{\prime \prime}$ glass slide of H\&E stained tissue. TURP is generally performed on patients with prostate volume $<75 \mathrm{cc}$. B, For prostate volume $>75 \mathrm{cc}$, an open or robotic simple prostatectomy is performed. In this procedure, the surgeon first manually separates the loosely connected transition zone from the peripheral zone, and then surgically removes the transition zone as a single piece. Because of the specimen size, most simple prostatectomies are best visualized on $2^{\prime \prime} \times 3^{\prime \prime}$ glass slides to preserve contiguity. C, A specimen with an embedded glandular nodule (outlined in B) demonstrates how demarcated and distinct the morphology and cellular biology of glandular nodules can be from adjacent inter-nodular regions by showing remarkable differences in inflammation (CD45 in brown) and differentiation (AR in red). 


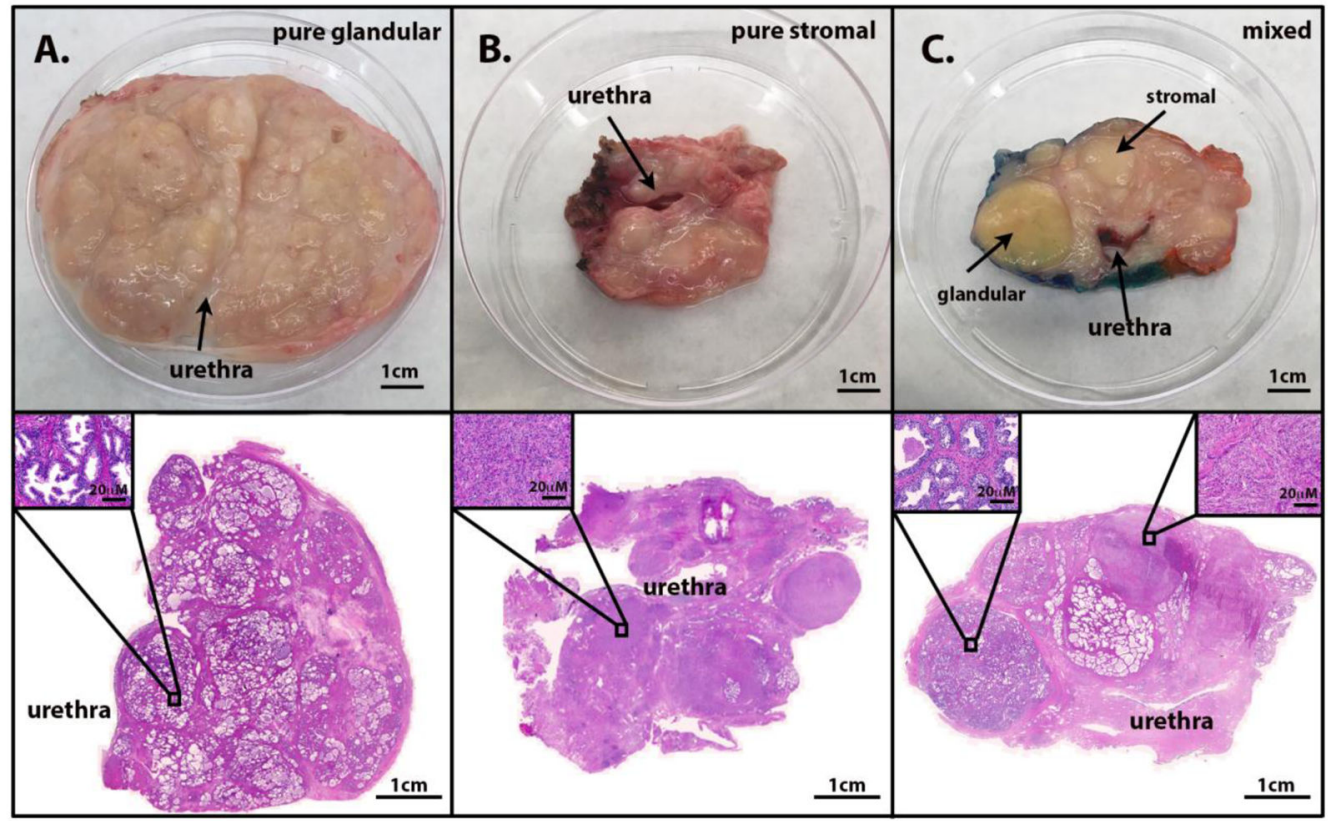

Figure 4. Examples of pure and mixed phenotypes in BPH

A, A coronal section of a purely glandular $250 \mathrm{cc}$ BPH specimen is shown in a $10 \mathrm{~cm}$ dish. Only one hemisphere of the specimen fit onto a $2^{\prime \prime} \times 3^{\prime \prime}$ glass slide subjected to high resolution scanning. B, A 100cc BPH specimen with a purely stromal composition. C, A 130cc specimen with both stromal and glandular hyperplasia. 


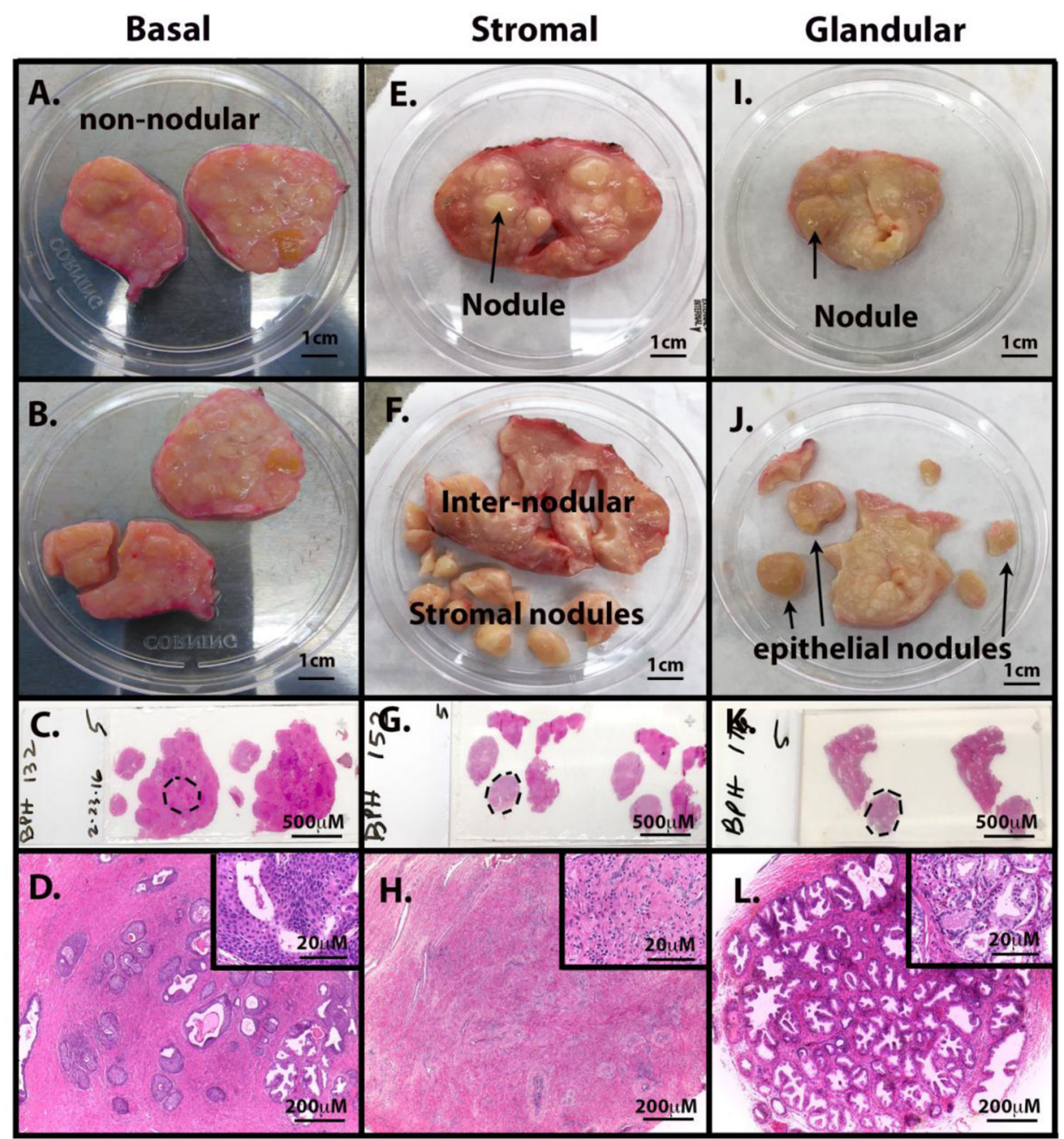

Figure 5. Heterogeneous cellular phenotypes of macrodissected gross morphological features Three main phenotypes of cellular hyperplasia are represented: basal (A-D), stromal (E-F), and glandular (I-L). Gross morphological features are noted before (A, E, I) and after macrodissection $(\mathrm{B}, \mathrm{F}, \mathrm{J})$. Macrodissected pieces of tissue are then mounted onto glass slides $(\mathrm{C}, \mathrm{G}, \mathrm{K})$ and outlined prominent features are displayed at higher magnification in $\mathrm{D}, \mathrm{H}$, and L. 
A. Clinical data

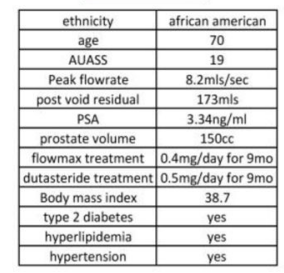

C.

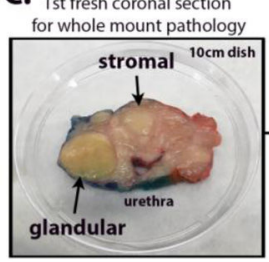

2nd fresh coronal section for macrodissection and digestion

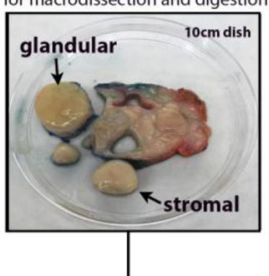

Flow cytometry on single cells isolated from each phenotype
B.

MRI data

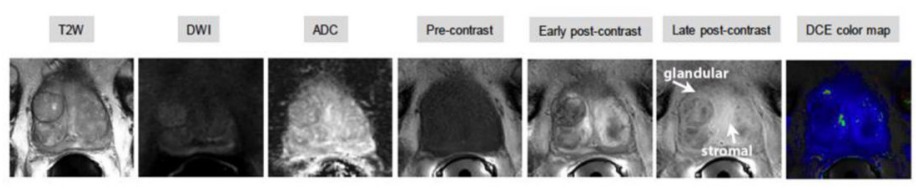

D.
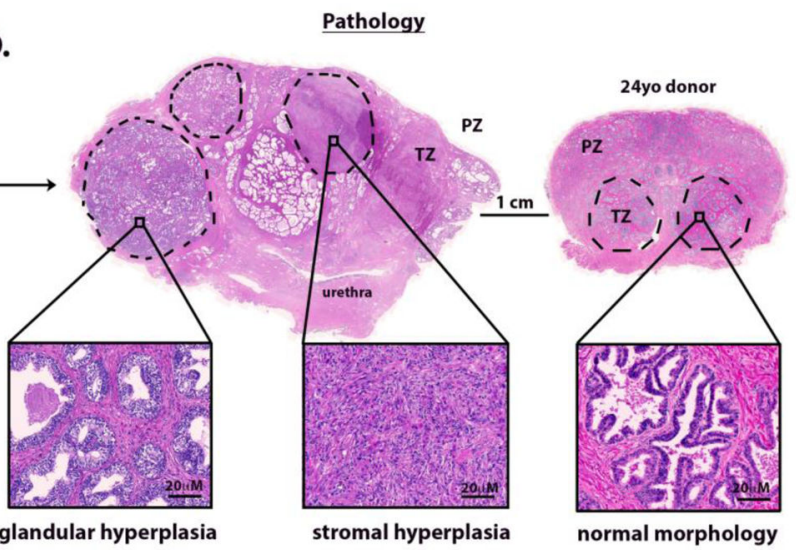

E.

glandular nodule $10^{5} 7$ Leukocytes
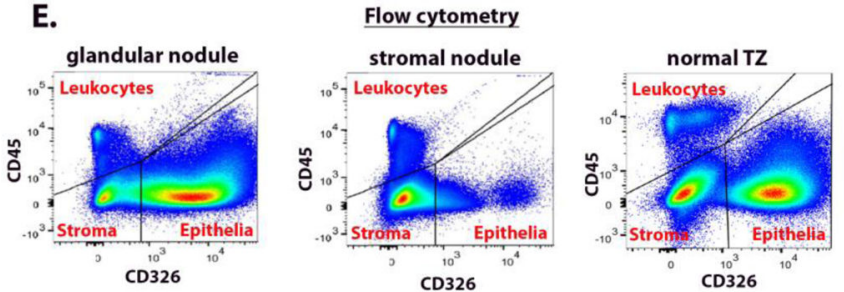

Figure 6. Clinical diagnostic and experimental approach to single cell type-specific analysis of glandular and stromal BPH phenotypes

A, Clinical data is collected on each patient to determine BPH/LUTS severity. B, T2weighted, diffusion-weighted magnetic resonance images (MRI) procured by a 3T MRI system are registered with coronal sections of tissue captured using custom 3D molds. C, Whole mounts on large-format glass slides are then scanned in high resolution to assess regional pathology. E, A second fresh coronal section is also sent to the lab for macrodissection and digestion into single cells. Flow cytometry scatter plots of single cells in stromal and glandular nodules macrodissected from fresh tissue demonstrate altered ratios of stroma to epithelia in regional phenotypes from the same patient compared to a scatter plot of cells harvested from a normal transition zone resected from a 24 year old donor. 